\title{
MANEJO DE PLANTAS DANINHAS EM SOJA GENETICAMENTE MODIFICADA TOLERANTE AO GLYPHOSATE ${ }^{1}$
}

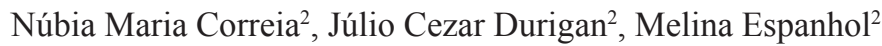

\section{ABSTRACT \\ WEED CONTROL IN GENETICALLY \\ MODIFIED GLYPHOSATE-TOLERANT SOYBEAN}

The transgenic production systems, as well as conventional systems, require, in addition to chemical control, the adoption of other weed management strategies. This study was developed to evaluate the weed chemical control in glyphosate tolerant soybean, associated to cover crops cultivated in the autumn/winter. The experiment was carried out under field conditions at the FCAV/Unesp, Jaboticabal, São Paulo State, Brazil. A randomized split-plot block design was used, with four replications. St. Lucia Grass (Brachiaria brizantha 'Marandu'), forage millet (Pennisetum americanum 'BN2'), and a treatment with spontaneous growth vegetation were evaluated for plots, and, for subplots, the herbicides glyphosate, chlorimuron - ethyl plus lactofen, and fluazifop-pbutyl, in a sequential spraying, and two controls without any application. Grass cover contributed to the chemical control, suppressing weeds, and the single application of $720 \mathrm{~g}$ a.e. $\mathrm{ha}^{-1}$ of glyphosate, independently of the cover crop cultivated in the autumn/winter, was sufficient for adequately controlling Acanthospermum hispidum, Alternanthera tenella, Amaranthus sp., Bidens pilosa, Xanthium strumarium, Cenchrus echinatus, Digitaria sp., and Eleusine indica, with results similar to the treatment (chlorimuron-ethyl + lactofen) + fluazifop-p-buthyl. When compared to the weeded control, the herbicides did not affect plants height, dry matter of the aerial parts, mass of 100 grains, and grain yield. Soybean plants grown over St. Lucia Grass and forage millet presented a higher height, however, no other feature was influenced by the cover crop.

KEY-WORDS: Brachiaria brizantha; Pennisetum americanum; no-tillage; Roundup Ready; spontaneous vegetation.

\section{INTRODUÇÃO}

O glyphosate possui amplo espectro de ação de plantas daninhas, porém, o uso exclusivo deste herbicida, em áreas de soja geneticamente modificada (transgênica), pode apresentar limitações. Algumas

\section{RESUMO}

Os sistemas de produção transgênicos, assim como os convencionais, exigem, além do controle químico, a adoção de outras estratégias de manejo de plantas daninhas. Objetivouse, com este trabalho, avaliar o controle químico de plantas daninhas, em soja geneticamente modificada (transgênica) tolerante ao herbicida glyphosate associado a coberturas vegetais, na entressafra. $\mathrm{O}$ experimento foi instalado em área experimental da FCAV/Unesp, Jaboticabal (SP). O delineamento experimental foi o de blocos ao acaso, em esquema de parcelas subdivididas, com quatro repetições. Nas parcelas, foram avaliadas as coberturas vegetais de Brachiaria brizantha (braquiarão cv. Marandu), Pennisetum americanum (milheto forrageiro cv. BN2) e vegetação espontânea, e, nas subparcelas, os herbicidas glyphosate, chlorimuron - ethyl + lactofen em mistura e fluazifop-p-butyl em aplicação sequencial, além de duas testemunhas sem aplicação. A cobertura com braquiarão contribuiu para o controle químico, exercendo supressão das plantas daninhas. A aplicação única de $720 \mathrm{~g}$ e.a. ha-1 de glyphosate, independentemente da cobertura vegetal utilizada na entressafra, foi suficiente para o controle adequado de Acanthospermum hispidum, Alternanthera tenella, Amaranthus sp., Bidens pilosa, Xanthium strumarium, Cenchrus echinatus, Digitaria sp. e Eleusine indica, com resultados similares ao tratamento (chlorimuron-ethyl + lactofen) + fluazifop-p-buthyl. Comparados à testemunha capinada, os herbicidas testados não afetaram a altura das plantas, massa seca da parte aérea, massa de 100 grãos e a produtividade de grãos. As plantas de soja crescidas sobre os resíduos vegetais de braquiarão e milheto forrageiro apresentaram maior altura, porém, nenhuma outra característica avaliada na cultura foi influenciada pelas coberturas.

PALAVRAS-CHAVE: Brachiaria brizantha; Pennisetum americanum; plantio direto; Roundup Ready; vegetação espontânea.

espécies podem requerer doses mais elevadas de glyphosate, aplicação sequencial ou, ainda, a adição de outro herbicida, para controle adequado (Ateh \& Harvey 1999). Além disto, o uso contínuo de herbicidas com o mesmo mecanismo de ação pode aumentar a pressão de seleção de biótipos de plantas daninhas

1. Trabalho recebido em fev./2010 e aceito para publicação em jun./2011 (nº registro: PAT 8807/ DOI: 10.5216/pat.v41i2.8807).

2. Universidade Estadual Paulista (Unesp), Campus de Jaboticabal, Departamento de Fitossanidade, Jaboticabal, SP, Brasil.

E-mails: correianm@fcav.unesp.br,jcdurigan@fcav.unesp.br,melespanhol@hotmail.com.br. 
resistentes. No Brasil, foram registrados biótipos resistentes ao glyphosate de Conyza canadensis, Conyza bonariensis, Digitaria insularis, Euphorbia heterophylla e Lolium multiflorum (Heap 2011).

Embora o agricultor tenha conhecimento de que as mudanças na comunidade infestante podem ser agravadas pela presença de espécies de difícil controle, ele não deixará de utilizar a tecnologia, enquanto verificar vantagens financeiras e, principalmente, operacionais (Gazziero 2006). No entanto, existe o risco da seleção de espécies indesejáveis, com o aumento de aplicações de glyphosate.

Nos EUA, houve aumento na infestação de Ipomoea sp. e Commelina sp., nos campos de produção de soja transgênica, e de plantas daninhas anuais de inverno com tolerância natural ao glyphosate (Culpepper 2006). Portanto, os sistemas de produção transgênicos, assim como os convencionais, exigem a adoção de outras estratégias de manejo, além do controle químico. Mesmo nos locais com maior ocorrência de plantas daninhas de fácil controle pelo glyphosate, o uso frequente e único deste herbicida deve ser evitado. Outra prática agrícola que deve ser abolida é a manutenção de vegetação espontânea no período de outono/inverno, em áreas de produção de grãos, pois ela será responsável pelo aumento do banco de diásporos de plantas daninhas no solo. $\mathrm{O}$ cultivo de culturas de cobertura na entressafra visa a solucionar este problema e melhorar a biodiversidade dos sistemas agrícolas.

As espécies utilizadas como cobertura podem ocasionar alterações na fertilidade do solo, favorecer o controle das erosões eólica e hídrica, auxiliar na conservação da umidade do solo, pela redução da evaporação e aumento da infiltração, aumentar o teor de matéria orgânica, melhorar as propriedades físicas e biológicas do solo, reduzir o escoamento superficial de produtos fitossanitários e nutrientes, diminuir a amplitude da variação térmica no solo e influenciar, significativamente, no manejo das plantas daninhas.

A este respeito, a palha mantida sobre o solo altera a umidade, luminosidade e temperatura, principais características envolvidas no controle da dormência, e, consequentemente, na germinação das sementes de plantas daninhas. Além disto, a cobertura pode prejudicar as plântulas em desenvolvimento, pela barreira física, causando o estiolamento das mesmas e tornando-as suscetíveis aos danos mecânicos. Pode, ainda, proporcionar alterações químicas decorrentes da alelopatia, disponibilização de nu- trientes e alterações da relação C/N. Finalmente, pode favorecer o desenvolvimento de insetos e fungos que se alimentam ou se hospedam nas sementes e na parte aérea das plantas daninhas (Pitelli \& Durigan 2001).

A hipótese do estudo é que o controle de plantas daninhas pelo herbicida glyphosate, na cultura da soja transgência, é beneficiado pela cobertura vegetal utilizada na entressafra, não sendo necessário o uso de doses maiores ou de aplicação sequencial sobre determinada cobertura, e que o desenvolvimento e a produtividade da soja não são afetados pelo herbicida. Portanto, objetivou-se, com este trabalho, avaliar a produtividade da cultura da soja e o controle químico de plantas daninhas, em soja transgênica tolerante ao herbicida glyphosate associado a coberturas vegetais, na entressafra.

\section{MATERIAL E MÉTODOS}

O experimento foi instalado em campo, de março de 2007 a abril de 2008, em área experimental da FCAV/Unesp, Jaboticabal (SP).

$\mathrm{O}$ delineamento experimental foi o de blocos ao acaso, em esquema de parcelas subdivididas, com quatro repetições. Nas parcelas, foram avaliadas três coberturas vegetais: Brachiaria brizantha (braquiarão cv. Marandu), Pennisetum americanum (milheto forrageiro cv. BN2) e vegetação espontânea, e, nas subparcelas, quatro tratamentos com herbicidas: glyphosate $\left(720 \mathrm{~g} \mathrm{ha}^{-1}\right.$ e $1.200 \mathrm{~g} \mathrm{ha}^{-1}$ de equivalente ácido (e.a.) em aplicações únicas e $960 \mathrm{~g}$ e.a. ha-1 mais 720 g e.a. ha ${ }^{-1}$ em aplicação sequencial); chlorimuron ethyl + lactofen $\left(10+96\right.$ g i.a. ha $\left.{ }^{-1}\right)$ em mistura e fluazifop-p-butyl (187,5 g i.a. ha $\left.{ }^{-1}\right)$ em aplicação sequencial, além de duas testemunhas sem aplicação. Uma testemunha foi mantida infestada até o fim do ciclo da cultura e a outra capinada até o fechamento do dossel das plantas de soja.

Na segunda semana do mês de março de 2007, as coberturas vegetais de braquiarão e milheto forrageiro foram semeadas a lanço, utilizando-se $32 \mathrm{~kg} \mathrm{ha}^{-1}$ de sementes de milheto forrageiro e $25 \mathrm{~kg} \mathrm{ha}^{-1}$ de braquiarão. Em uma parcela, manteve-se a vegetação espontânea, formada naturalmente na área.

Quinze dias antes da semeadura da soja, efetuou-se a aplicação de $1,44 \mathrm{~kg}$ e.a. ha ${ }^{-1}$ de glyphosate, para eliminação das plantas presentes na área experimental. Após 12 dias, foi realizada nova aplicação de glyphosate $\left(1,44\right.$ e.a. $\left.\mathrm{kg} \mathrm{ha}^{-1}\right)$. No mesmo dia da semeadura da soja, foram realizadas, em cada parcela, 
três amostragens de $0,5 \mathrm{~m}^{2}$, para a quantificação da palha equivalente a um hectare.

A recomendação de adubação foi feita com base na análise do solo e na necessidade nutricional das plantas, consistindo na aplicação de $250 \mathrm{~kg} \mathrm{ha}^{-1}$ da fórmula 08-20-20. No sulco de semeadura, também foi aplicado o inoculante líquido Urulec-L, na quantidade de $3 \mathrm{~mL} \mathrm{~kg}^{-1}$ de sementes de soja.

A soja (cv. M-SOY 8008 RR) foi semeada no dia 5 de dezembro, no sistema de semeadura direta, a uma profundidade de $5,0 \mathrm{~cm}$, com $0,45 \mathrm{~m}$ de distância entre linhas e 21 sementes por metro. As parcelas (coberturas vegetais) foram constituídas por $3,15 \mathrm{~m}$ de largura e 30,0 m de comprimento e as subparcelas (tratamentos de herbicidas) por 3,15 $\mathrm{m}$ de largura e 5,0 m de comprimento, com cinco linhas centrais e 4,0 m de comprimento.

Quando as plantas daninhas apresentaram de 4 a 5 folhas definitivas totalmente expandidas (para as dicotiledôneas) e de 2 a 3 perfilhos (para as monocotiledôneas), foi realizada a aplicação única de glyphosate, nas doses indicadas. No tratamento sequencial, a primeira aplicação de glyphosate ocorreu com as plantas dicotiledôneas de 3 a 4 folhas definitivas e as gramíneas ainda não perfilhadas. A aplicação sequencial foi realizada 14 dias após a primeira aplicação. A aplicação da mistura chlorimuron + lactofen foi realizada quando as plantas encontravam-se com 3 a 4 folhas definitivas. Neste tratamento, o controle de gramíneas foi feito com a aplicação de fluazifop-p-butyl, quando estas apresentaram de 3 a 5 perfilhos. A comunidade infestante foi composta por Acanthospermum hispidum (17,8 plantas $\left.\mathrm{m}^{-1}\right)$, Alternanthera tenella $\left(2,8\right.$ plantas $\left.\mathrm{m}^{-1}\right)$, Amaranthus sp. $\left(0,2\right.$ planta $\left.\mathrm{m}^{-1}\right)$, Bidens pilosa $\left(0,7\right.$ planta $\left.\mathrm{m}^{-1}\right)$, Xanthium strumarium (2,2 plantas $\left.\mathrm{m}^{-1}\right)$, Cenchrus echinatus $\left(4,5\right.$ plantas $\left.\mathrm{m}^{-1}\right)$, Digitaria sp. $\left(15,8\right.$ plantas $\left.\mathrm{m}^{-1}\right)$ e Eleusine indica $\left(3,3\right.$ plantas $\left.\mathrm{m}^{-1}\right)$. A densidade de plantas apresentada foi a média obtida para toda a área experimental.

Os herbicidas foram aplicados com auxílio de pulverizador costal, pressurizado com $\mathrm{CO}_{2}$ à pressão constante de $2,9 \mathrm{kgf} \mathrm{cm}^{-2}$, munido de barra com seis pontas de pulverização em leque 11002 , espaçadas em $0,5 \mathrm{~m}$, o que proporcionou a aplicação de $200 \mathrm{~L} \mathrm{ha}^{-1}$ de volume de calda.

Aos 14 e 21 dias após a aplicação (DAA) dos herbicidas, foram realizadas avaliações visuais de controle das plantas daninhas, atribuindo-se notas de $0 \%$ a $100 \%$, em que zero representa a ausência de injúrias visuais e $100 \%$ a morte da planta (SBCPD 1995). Aos 64 dias após a semeadura (DAS), coletou-se a parte aérea das plantas daninhas, em duas áreas de $0,25 \mathrm{~m}^{2}$ cada $(0,5 \mathrm{~m} \times 0,5 \mathrm{~m})$, escolhidas, aleatoriamente, dentro da área útil das subparcelas. $\mathrm{O}$ material foi seco em estufa de circulação forçada de ar, a $50^{\circ} \mathrm{C}$, até atingir massa constante.

Aos 7, 14 e 21 DAA, foram avaliadas possíveis injúrias visuais nas plantas de soja, utilizando-se escala de notas em percentagem (SBCPD 1995). Aos 64 DAS, foram quantificadas a altura das plantas $(\mathrm{cm})$ de soja, considerando-se a distância entre o colo e a extremidade da haste principal, e a massa seca da parte aérea das plantas $\left(\mathrm{g}\right.$ planta $\left.{ }^{-1}\right)$. Para estas avaliações, foram amostradas dez plantas por subparcela. Ao final do ciclo, foram avaliadas a produtividade de grãos e a massa de 100 grãos.

Para a obtenção da produtividade por subparcela, três linhas com 4,0 $\mathrm{m}$ de comprimento foram colhidas mecanicamente, sendo, posteriormente, trilhadas, e a umidade dos grãos corrigida para 13\%.

Os resultados obtidos foram submetidos a análise de variância, pelo teste F. As médias dos efeitos das coberturas vegetais e dos tratamentos de herbicidas, quando significativas, foram comparadas pelo teste Tukey. As interações, quando significativas, foram desdobradas e as médias comparadas pelo teste Tukey. Os dados originais das notas de fitointoxicação e de controle foram transformados em raiz quadrada de x. Os testes de média foram efetuados a $5 \%$ de probabilidade.

\section{RESULTADOS E DISCUSSÃO}

As coberturas vegetais afetaram, significativamente, a altura das plantas e os tratamentos de herbicidas as notas de fitointoxicação, aos 7 e 14 DAA, e a produtividade de grãos. Os tratamentos estudados (isolados ou a interação entre eles) não influenciaram na massa seca da parte aérea e na massa de 100 grãos de soja. Para as avaliações visuais de controle e massa seca das plantas daninhas, a interação coberturas $\mathrm{x}$ tratamentos herbicidas foi significativa para todas as variáveis avaliadas.

$\mathrm{Na}$ avaliação inicial, o glyphosate, aplicado de forma isolada ou sequencial, ocasionou danos visuais às plantas de soja, classificados como nulos ou muito leves, os quais desapareceram, aos 14 DAA(Tabela 1). A aplicação de chlorimuron em mistura com lactofen ocasionou injúrias visuais mais acentuadas. Porém, os 
Tabela 1. Fitointoxicação por herbicidas de plantas de soja transgênica, avaliadas aos 7, 14 e 21 dias após a aplicação (DAA), e produtividade da soja transgênica (Jaboticabal, SP, 2007/2008).

\begin{tabular}{|c|c|c|c|c|c|}
\hline \multirow{3}{*}{ Tratamentos } & \multirow{2}{*}{ Doses } & \multicolumn{3}{|c|}{ Fitointoxicação } & \multirow{2}{*}{ Produtividade } \\
\hline & & $7 \mathrm{DAA}$ & $14 \mathrm{DAA}$ & $21 \mathrm{DAA}$ & \\
\hline & $\mathrm{g} \mathrm{ha}^{-1}$ & & $\%$ & & $\mathrm{~kg} \mathrm{ha}^{-1}$ \\
\hline 1- Glyphosate & 720 & $0,83 \mathrm{ab}^{(1)}$ & $0,00 \mathrm{a}$ & 0,00 & $4157,04 \mathrm{a}$ \\
\hline 2- Glyphosate & 1200 & $3,75 \mathrm{~b}$ & $0,00 \mathrm{a}$ & 0,00 & $4082,30 \mathrm{a}$ \\
\hline 3-Glyphosate & $960 \ldots 720^{(2)}$ & $3,75 \mathrm{~b}$ & $0,00 \mathrm{a}$ & 0,00 & 3984,41 a \\
\hline 4- Chlorimuron-ethyl & 10 & & & & \\
\hline Lactofen & 96 & $30,83 \mathrm{c}$ & $12,08 \mathrm{~b}$ & 0,00 & 4291,88 a \\
\hline Fluazifop-p-buthyl & 187,5 & & & & \\
\hline 5- Testemunha capinada & - & $0,00 \mathrm{a}$ & $0,00 \mathrm{a}$ & 0,00 & $4095,40 \mathrm{a}$ \\
\hline 6- Testemunha infestada & - & $0,00 \mathrm{a}$ & $0,00 \mathrm{a}$ & 0,00 & $3418,62 \mathrm{~b}$ \\
\hline CV1 $(\%)$ & & 48,60 & 23,73 & - & 11,89 \\
\hline CV2 (\%) & & 71,53 & 25,17 & - & 8,88 \\
\hline
\end{tabular}

(1) Médias seguidas pelas mesmas letras minúsculas, nas colunas, não diferem, significativamente, pelo teste Tukey, a $5 \%$. As médias das quatro repetições apresentadas para notas de fitointoxicação referem-se aos dados originais, que foram transformados em $\sqrt{x}$, para realização da análise estatística. ${ }^{(2)}$ Aplicação sequencial realizada 14 dias após a primeira aplicação.

sintomas ficaram restritos às folhas que receberam o jato de pulverização e diminuíram ao longo do tempo. Aos 21 DAA, não foram mais observados danos visíveis, devido à recuperação das plantas.

Independentemente da cobertura vegetal utilizada na entressafra, os herbicidas glyphosate e (chlorimuron + lactofen) + fluazifop não afetaram a produtividade de grãos de soja, diferindo, apenas, da testemunha infestada (Tabela 1). O efeito fitotóxico de glyphosate em soja transgênica ainda é bastante discutido e os resultados bem variáveis. Apesar da redução no conteúdo de clorofila, biomassa de nódulos e conteúdo de legmoglobina (Reddy et al. 2000) e fixação e acúmulo de nitrogênio nas raízes (King et al. 2001) de algumas variedades transgênicas, a maioria dos trabalhos comprovaram ausência de efeito significativo na produtividade de grãos (Norsworthy 2004, Correia \& Durigan 2007, Nurse et al. 2007, Zablotowicz \& Reddy 2007, Correia et al. 2008). Pesquisas reportaram redução na produção de grãos de soja sob condições de estresse, como baixo aproveitamento de água, por certas variedades de soja geneticamente modificadas (Elmore et al. 2001, King et al. 2001).

A soja crescida sobre palha de braquiarão e milheto forrageiro teve maior altura (média de $76,50 \mathrm{~cm}$ ) do que aquelas sobre resíduos vegetais da vegetação espontânea $(69,29 \mathrm{~cm})$ (dados não apresentados). Apesar do acréscimo médio de $9,4 \%$ na altura, isto não refletiu em outras características avaliadas, como a produtividade de grãos (Tabela 1).
Aos 14 DAA, não houve diferença entre os tratamentos herbicidas, para a cobertura de braquiarão (Tabela 2). Este fato indica o efeito positivo desta cobertura no controle de plantas daninhas, na cultura em sucessão, sob sistema plantio direto. Isto ficou evidente, em comparação às testemunhas dos resíduos de milheto forrageiro e vegetação espontânea. Para milheto forrageiro, os herbicidas foram eficazes no controle das plantas daninhas, diferindo da testemunha sem aplicação, enquanto, na ausência de espécies de cobertura, constatou-se elevada infestação de gramíneas, nas parcelas do tratamento convencional, similar à da testemunha sem herbicida. A aplicação do fluazifop no tratamento (chlorimuron + lactofen) + fluazifop foi realizada no mesmo dia desta avaliação, justificando o baixo controle de gramíneas, para este tratamento. Neste caso, a aplicação de glyphosate diferiu da de (chlorimuron + lactofen) + fluazifop e ocasionou as maiores percentagens de controle.

Aos 21 DAA, com o cultivo de braquiarão na entressafra, a aplicação de herbicidas mostrou-se desnecessária, pois os herbicidas estudados não diferiram da testemunha não tratada (Tabela 2). Para milheto forrageiro e vegetação espontânea, os herbicidas não diferiram entre si, para o controle de plantas daninhas, mas diferiram da testemunha sem aplicação. Comparando-se as testemunhas não tratadas de cada cobertura vegetal, verificou-se que, sob vegetação espontânea, não houve controle; sob milheto forrageiro, o controle foi baixo (25\%); e, sob braquiarão, bom (88\%). Estes resultados comprovam o potencial da cobertura de braquiarão na supressão 
Tabela 2. Percentagem de controle de plantas daninhas, aos 14 e 21 dias após a aplicação (DAA) de herbicidas, em soja transgênica desenvolvida sobre a cobertura de braquiarão, milheto forrageiro e vegetação espontânea (pousio) (Jaboticabal, SP, 2007/2008).

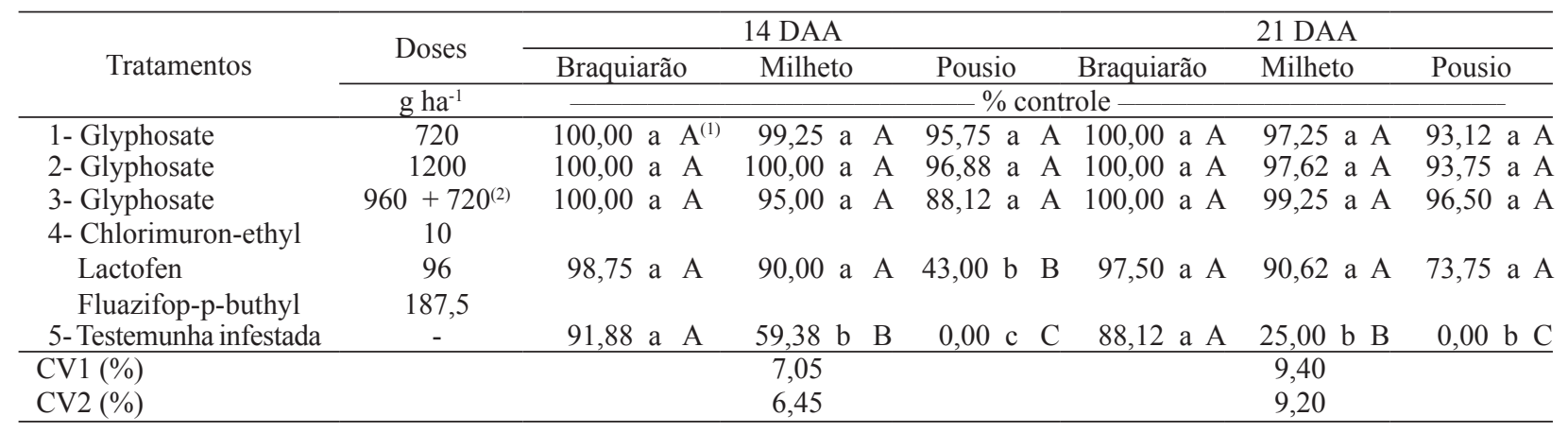

(1) Com base no teste Tukey, a 5\%, médias seguidas de letra minúsculas, nas colunas, comparam os tratamentos dentro de cada cobertura e, letras maiúsculas, nas linhas, comparam os três tipos de cobertura para cada tratamento, dentro de cada época de avaliação. As médias das quatro repetições apresentadas são oriundas dos dados originais, que foram transformados em $\sqrt{ } \mathrm{x}$, para realização da análise estatística. ${ }^{(2)}$ Aplicação sequencial realizada 14 dias após a primeira aplicação.

e controle de plantas daninhas, principalmente de espécies monocotiledôneas.

Na semeadura da soja, quantificou-se $7,75 \mathrm{tha}^{-1}$; 3,04 tha $^{-1}$; e 1,9 t ha $^{-1}$ de palha de braquiarão, milheto forrageiro e vegetação espontânea sobre o solo, respectivamente. No entanto, embora a apresentação e discussão dos resultados tenham sido feitas em função dos efeitos das espécies de cobertura após o estabelecimento da cobertura morta, deve-se levar em consideração o controle exercido pelas mesmas, quando ainda vivas. Experimentos de campo, com produção in locu dos resíduos vegetais, são extremamente complexos, pois envolvem a somatória do manejo adotado no período outono/inverno, com a instalação das culturas para produção de palha, e os efeitos propriamente ditos desta palha depositada sobre o solo.
Na avaliação de massa seca da parte aérea das plantas daninhas, realizada aos 64 DAS, houve maior acúmulo nas plantas da testemunha da vegetação espontânea, com valores superiores aos das testemunhas de braquiarão e milheto forrageiro (Tabela 3). Sob braquiarão, as plantas daninhas da testemunha infestada tiveram menor massa seca. Este resultado comprova que esta cobertura contribuiu com o controle químico, exercendo supressão das plantas daninhas.

Reddy (2003) observou que a biomassa das plantas daninhas (Echinochloa crus-galli, Brachiaria ramosa, Ipomoea lacunosa, Sesbania exaltata, Sida spinosa, Senna obtusifolia e Amaranthus hybridus) foi menor em soja transgênica, com aplicação única e sequencial de glyphosate, do que em soja conven-

Tabela 3. Massa seca da parte aérea das plantas daninhas, aos 64 dias após a semeadura de soja transgênica desenvolvida sobre cobertura de braquiarão, milheto forrageiro e vegetação espontânea (pousio) e pulverizada com herbicidas (Jaboticabal, SP, 2007/2008).

\begin{tabular}{|c|c|c|c|c|}
\hline \multirow{2}{*}{ Tratamentos } & $\operatorname{Doses}^{(1)}$ & Braquiarão & Milheto & Pousio \\
\hline & $\mathrm{g} \mathrm{ha}^{-1}$ & \multicolumn{3}{|c|}{ Massa seca $\left(\mathrm{g} 0,5 \mathrm{~m}^{-2}\right)$} \\
\hline 1- Glyphosate & 720 & 0,00 a $\mathrm{A}^{(1)}$ & 0,00 a $\mathrm{A}$ & 0,00 a $\mathrm{A}$ \\
\hline 2- Glyphosate & 1200 & 0,00 a $\mathrm{A}$ & 0,00 a $\mathrm{A}$ & 0,00 a $\mathrm{A}$ \\
\hline 3- Glyphosate & $960 \ldots 720^{(2)}$ & 0,00 a $\mathrm{A}$ & 0,00 a $\mathrm{A}$ & 0,00 a $\mathrm{A}$ \\
\hline 4- Chlorimuron-ethyl & 10 & & & \\
\hline Lactofen & 96 & 0,00 a $\mathrm{A}$ & 0,22 a $\mathrm{A}$ & 3,32 a $\mathrm{A}$ \\
\hline Fluazifop-p-buthyl & 187,5 & & & \\
\hline 5- Testemunha infestada & - & $23,57 \mathrm{~b} \mathrm{~A}$ & $93,58 \mathrm{~b}$ B & 179,73 b C \\
\hline CV1 (\%) & \multicolumn{4}{|c|}{159,70} \\
\hline CV2 (\%) & \multicolumn{4}{|c|}{145,45} \\
\hline
\end{tabular}


cional pulverizada com acifluorfen + bentazon + clethodim e com a associação desta mistura à aplicação sequencial de chlorimuron. Contudo, mesmo com diferenças no controle das plantas daninhas, os sistemas (convencional e transgênico) resultaram em produção similar de grãos. O glyphosate, em aplicação única e também sequencial, foi altamente eficaz no controle de Sorghum halepense, em soja transgênica (Griffin et. al. 2006). A aplicação única ocorreu aos 30 dias após a semeadura, quando a gramínea apresentava $40 \mathrm{~cm}$ de altura, nas doses $0,84 \mathrm{~kg} \mathrm{ha}^{-1}$; $1,12 \mathrm{~kg} \mathrm{ha}^{-1}$; e 2,24 kg ha-1 de glyphosate. Na aplicação sequencial (aos 30 e 60 dias após a semeadura), as plantas encontravam-se com $39 \mathrm{~cm}$ e $90 \mathrm{~cm}$ de altura, respectivamente. A aplicação de quizalofop, fluazifop ou clethodim resultou em controle médio de $90 \%$.

\section{CONCLUSÕES}

1. A cobertura com braquiarão contribuiu com o controle químico, exercendo supressão das plantas daninhas.

2. A aplicação única de $720 \mathrm{~g}$ e.a. ha ${ }^{-1}$ de glyphosate, independentemente da cobertura vegetal utilizada na entressafra, foi suficiente para o controle adequado de Acanthospermum hispidum, Alternanthera tenella, Amaranthus sp., Bidens pilosa, Xanthium strumarium, Cenchrus echinatus, Digitaria sp. e Eleusine indica, com resultados similares aos do tratamento (chlorimuron-ethyl + lactofen) + fluazifop-p-buthyl.

3. Comparados à testemunha capinada, os herbicidas testados não afetaram a altura das plantas, massa seca da parte aérea, massa de 100 grãos e a produtividade de grãos de soja. As plantas de soja crescidas sobre os resíduos vegetais de braquiarão e milheto forrageiro tiveram maior altura. Nenhuma outra característica avaliada na cultura foi influenciada pelas coberturas.

\section{REFERÊNCIAS}

ATEH, C. A.; HARVEY, R. G. Annual weed control by glyphosate in glyphosate-resistant soybean (Glycine max). Weed Technology, Champaign, v. 13, n. 2, p. 394-398, 1999.

CORREIA, N. M.; DURIGAN, J. C. Seletividade de diferentes herbicidas à base de glyphosate a soja RR. Planta Daninha, Viçosa, v. 25, n. 2, p. 375-379, 2007.
CORREIA, N. M.; DURIGAN, J. C.; LEITE, G. J. Seletividade da soja transgênica tolerante ao glyphosate e eficácia de controle de Commelina benghalensis com herbicidas aplicados isolados e em misturas. Bragantia, Campinas, v. 67, n. 3, p. 563-568, 2008.

CULPEPPER, A. S. Glyphosate induced weed shifts. Weed Technology, Champaign, v. 20, n. 2, p. 277-281, 2006.

ELMORE, R. W. et al. Glyphosate-resistant soybean cultivar yields compared with sister lines. Agronomy Journal, Madison, v. 93, n. 2, p. 408-412, 2001.

GAZZIERO, D. L. P. Soja transgênica: o que muda no manejo das plantas daninhas. In: CONGRESSO BRASILEIRO DE SOJA, 4., 2006, Londrina. Anais... Londrina: Embrapa Soja, 2006. p. 143-146.

GRIFFIN, J. L.; MILLER, D. K.; SALASSI, M. E. Jonhsongrass (Sorghum halepense) control and economics of using glyphosate-resistant soybean in fallowed sugarcane fields. Weed Technology, Champaign, v. 20, n. 4, p. 980-985, 2006.

HEAP, I. The international survey of herbicide resistant weeds. 2011. Disponível em: <http://www.weedscience. org >. Acesso em: 8 abr. 2011.

KING, C. A.; PURCELL, L. C.; VORIES, E. D. Plant growth and nitrogenase activity of glyphosate-tolerant soybean in response to foliar glyphosate applications. Agronomy Journal, Madison, v. 93, n. 1, p. 179-186, 2001.

NORSWORTHY, J. K. Broadleaved weed control in wide-row soybean (Glycine max) using conventional and glyphosate herbicide programmes. Crop Protection, Oxford, v. 23, n. 12, p. 1229-1235, 2004.

NURSE, R. E. et al. Is the application of a residual herbicide required prior to glyphosate application in no-till glyphosate-tolerant soybean (Glycine max)? Crop Protection, Oxford, v. 26, n. 4, p. 484-489, 2007.

PITELLI, R.; DURIGAN, J. C. Ecologia das plantas daninhas no sistema de plantio direto. In: ROSSELLO, R. D. Siembra directa em el Cono Sur. Montevideo: Procisur, 2001. p. 203-2010.

REDDY, K. N. Impact of rye cover crop and herbicides on weeds, yield, and net return in narrow-row transgenic and conventional soybean (Glycine max). Weed Technology, Champaign, v. 17, n. 1, p. 28-35, 2003.

REDDY, K. N.; HOAGLAND, R. E.; ZABLOTOWICZ, R. M. Effect of glyphosate on growth, chlorophyll, and nodulation in glyphosate-resistant and susceptible soybean (Glycine max) varieties. Journal New Seeds, Philadelphia, v. 2, n. 1, p. 37-52, 2000.

SOCIEDADE BRASILEIRA DA CIÊNCIA DAS PLANTAS DANINHAS (SBCPD). Procedimentos para instalação, avaliação e análise de experimentos com herbicidas. Londrina: SBCPD, 1995.

ZABLOTOWICZ, R. M.; REDDY, K. N. Nitrogenase activity, nitrogen content, and yield responses to glyphosate in glyphosate-resistant soybean. Crop Protection, Oxford, v. 26 , n. 3 , p. $370-376,2007$. 